\section{ASPECTOS AGROECOLÓGICOS NA PERSPECTIVA PARA A CRIAÇÃO DE UMA RESERVA DE DESENVOLVIMENTO SUSTENTÁVEL NA LOCALIDADE DE AREAIS DA RIBANCEIRA EM IMBITUBA, SANTA CATARINA, BRASIL}

\author{
AGROECOLOGICAL ASPECTS IN THE PRESPECTIVE FOR THE \\ CREATION OF A SUSTAINABLE DEVELOPMENT RESERVE IN THE \\ LOCALITY OF AREAIS DE RIBANCEIRA IN IMBITUBA, SANTA \\ CATARINA, BRAZIL
}

\title{
RESUMO
}

Os Areais da Ribanceira possuem características específicas que vêm sendo alvo de conflitos, devido ao aumento da pressão antrópica na área, influenciado pela especulação imobiliária e o etnocídio, afetando o território. Tal fato evidencia a importância de sua conservação e luta dos moradores e agricultores pelo direito à permanência e usufruto da terra, em detrimento dos interesses privados de grandes empresas nacionais. O estudo aborda aspectos agroecológicos como contribuição na criação de Reserva de Desenvolvimento Sustentável (RDS) na localidade dos Areais da Ribanceira de Imbituba, SC. Foi realizada uma visita à comunidade local, por meio da disciplina de Etnobiologia do Programa de Pós-Graduação em Ciências Ambientais da Universidade do Extremo Sul Catarinense. Constataram-se informações práticas de utilização de recursos naturais com características de aspectos agroecológicos, culturais e sociais e relatos das etnovariedades pertencentes à biodiversidade local. A diversidade de espécies encontradas sofre ameaça devido à degradação antrópica. Os Areais da Ribanceira merecem atenção das instituições públicas e privadas, além de ONGS para auxiliar na conservação ambiental e etnocultural. Os moradores precisam empoderamento da importância desse patrimônio sociocultural e dar continuidade às atividades de subsistência, utilizando recursos naturais locais de forma sustentável, garantindo que esse conhecimento seja repassado para as futuras gerações.

Engenheiro Agrônomo, Mestre em Geografia (UNESC). E-mail: mrg@unesc.net

Carlyle Torres Bezerra de Menezes

Engenheiro de Minas, Engenharia Mineral (UNESC). E-mail: cbm@unesc.net

Vanilde CitadiniZanette

Bióloga, Doutora em Ecologia e Recursos Naturais (UNESC). E-mail: vcz@unesc.net

Desenvolvimento.

\section{ABSTRACT}

The Areais da Ribanceira have specific and peculiar features, however, the increase of the anthropic pressure in the area has affected significantly, evidencing the importance of its conservation. Local residents and farmers have struggled to find their rights to land but are settling in a territory of conflicts of interest. We can conclude that the site is targeted by private interests of large national corporations, real state speculation and ethnocultural epistemicide that deconstructs territoriality, however, without success. The study discusses agroecological aspects as a contribuition to the of Sustainable Development Reserve (RDS) in locality the Areais da Ribanceira in Imbituba, SC. An on-site visit was made to the local community, through the Ethnobiology discipline of the Post-Graduate Program in Environmental Sciences of the University of Extremo Sul Catarinense. Practical information on the use of natural resources with characteristics of agroecological, cultural and social aspects and reports of ethnovarieties belonging to local biodiversity was registered. We can conclude that the locality is targeted by large national companies' private interests, and that the inhabitants face difficulties in relation to territoriality. The diversity of species found is also 
threatened by anthropic degradation in that area. The Areais da Ribanceira deserves special attention from public and private institutions and NGOs to assist in local environmental and ethnocultural conservation. Residents need to be empowered to the importance of this socio-cultural heritage and to continue subsistence activities, using local natural resources sustainably way, ensuring that this traditional knowledge be passed on to future generations.

Keywords: Environmental conservation. Agroecology. Sustainability. Development. 
Revista Tecnologia e Ambiente, v. 25, 2019, Criciúma, Santa Catarina/SC ISSN Eletrônico 2358-9426 e ISSN Impresso 1413-8131

\section{INTRODUÇÃO}

Os Areais da Ribanceira são terras de uso comum, utilizadas por agricultores e pescadores da região. Areais refere-se ao solo da região, que é composto por área e vegetação de restinga, destacando-se a população de butiá (Butia catarinensis Noblick \& Lorenzi) e uma enorme diversidade de espécies nativas. Já Ribanceira refere-se à inclinação do terreno, que vai descendo do Morro do Mirim até chegar ao nível do mar, na Praia da Ribanceira. A duna dos "três Mares" é assim chamada por possui em seu entorno o mar de dentro (Mirim), o mar grosso e o mar da Ibiraquera (lagoas) (HANAZAKI et al., 2012; MOMBELLI et al., 2011).

Segundo Campos Pinto et al. (2012), até a década de 1970 a população de Imbituba vivia principalmente da pesca e agricultura como forma de subsistência, além do extrativismo de espécies nativas. Contudo, apesar das diversas mudanças socioeconômicas, essas atividades continuam sendo realizadas, assegurando a alimentação e a saúde de muitos imbitubenses.

Um dos principais conflitos encontrados ocorre em relação à territorialidade, devido à ausência de escrituras, que fez com que muitos moradores perdessem seus hectares de terra (de 278 ha para 23 ha) às empresas nacionais que ali se instalaram. Mineradoras também provocaram impactos negativos devido à extração ilegal de areia. Portanto, esse território, utilizado há décadas para agricultura e extrativismo, vem sendo reduzido pela instalação de indústrias e pela especulação imobiliária (CAMPOS PINTO et al., 2012). Segundo Mombelli (2013, p. 325), “[...] apesar dos direitos das Comunidades Tradicionais estarem assegurados pela Constituição de 1988 e dispositivos legais internacionais, esses são sistematicamente ignorados diante do mito do progresso". De acordo com a autora, esse grupo social é visto como entrave aos projetos e alvo de políticas de restrição de direitos pelo Estado Brasileiro.

Para evitar que a degradação ambiental tomasse conta desse território, as famílias de agricultores, em 2002, fundaram a Associação Comunitária Rural de Imbituba (ACORDI) (MOMBELLI et al., 2011). No contexto da mobilização desta comunidade, buscou-se elaborar a proposta para a criação de uma unidade de conservação de uso sustentável, tendo sido escolhida como melhor alternativa, uma Reserva de Desenvolvimento Sustentável (RDS), a fim de assegurar a comunidade o direito ao uso desse território (MOMBELLI, 2013).

O manejo e as práticas tradicionais dos recursos vegetais locais fortalecem a cultura dessa comunidade secular, convivendo em harmonia, plantando e colhendo alimentos para sua subsistência. Muitos estudiosos têm optado por apoiar e realizar pesquisas no local, ressaltando o empoderamento da comunidade, bem como, seus aspectos agroecológicos, biológicos e legais. Nesse sentido, instituições de ensino superior públicas, privadas e comunitárias, como UFSC, UNISUL e UNESC, têm participado de ações por meio de projetos, promovendo estudos que envolvem a comunidade, os 
aspectos culturais, agroecológicos, biológicos e legais, contribuindo para a visibilidade da comunidade e seu empoderamento (CAMPOS PINTO et al., 2012; HANAZAKI, N. et al., 2012; ZANK; HANAZAKI, 2012; ZANK; HANAZAKI; MELLO 2015).

Os estudos de Zank et al. (2012, p. 35) consideram que “[...] as discussões sobre aspectos do empoderamento assumem um papel fundamental para a conservação da biodiversidade na lógica de unidades de conservação (UC) de uso sustentável”. Assim, a RDS apresenta-se como estratégia de garantia de território para as comunidades tradicionais e manutenção do modo de vida dessas populações. No entanto, para que a conservação ambiental se efetive, enquanto principal objetivo das UCs, é fundamental que essas populações estejam conscientes de seus direitos e responsabilidades e sejam capazes de gerir esse território de forma sustentável (ZANK et al., 2012).

Nesse sentido, a agroecologia, segundo De Aquino e De Assis (2007, p. 137),

É um instrumento importante na implementação de estratégias para viabilizar produções agrícolas em pequena escala sob administração familiar, em função principalmente da baixa dependência de insumos externos dos sistemas de produção preconizados, que procuram manter ou recuperar a paisagem e a biodiversidade dos agroecossistemas.

A fim de viabilizar a produção agroecológica, o uso consciente e sustentável dos recursos vegetais é fundamental para a manutenção e permanência do modo de vida. A população local constitui, dessa forma, parte da rica sociobiodiversidade brasileira, mantida por meio da intrínseca relação do homem com a natureza (CASTELLANO, 2015). Esse restabelecimento da relação de equilíbrio entre o homem e o ambiente, com vistas à produção de produtos agrícolas ou agrossilviculturais (alimentos, fibras, medicamentos), pode ser reconstruído por meio da agroecologia. As práticas e técnicas agrícolas com orientação ecológica são reconhecidas por várias denominações como "agricultura orgânica", "permacultura" ou "agricultura sustentável". Mais recentemente, o termo unificador "agroecologia" agrupou conhecimentos científicos com as práticas de agricultura baseada em princípios ecológicos (CAPRA; LUISI, 2014).

Para Altieri (2004), a agroecologia baseia-se no conceito de agroecossistemas como unidade de análise, tendo como principal propósito proporcionar bases científicas para apoiar o processo de transição do atual modelo de agricultura convencional, para estilos de agricultura sustentável. A agroecologia, na concepção de Altieri (2004, p. 23), municia um método de trabalho para a compreensão mais intensa “[...] tanto da natureza dos agroecossistemas como dos princípios segundo os quais eles funcionam".

Trata-se de uma nova abordagem que integra os princípios agronômicos, ecológicos e socioeconômicos à compreensão e avaliação do efeito das tecnologias sobre os sistemas agrícolas e a sociedade como um todo. Utiliza os agroecossistemas como unidade de estudo, ultrapassando a visão unidimensional - genética, agronomia, edafologia -, incluindo dimensões ecológicas, sociais e 
Revista Tecnologia e Ambiente, v. 25, 2019, Criciúma, Santa Catarina/SC ISSN Eletrônico 2358-9426 e ISSN Impresso 1413-8131

culturais. Uma abordagem agroecológica incentiva os pesquisadores a penetrar no conhecimento e nas técnicas dos agricultores e a desenvolver agroecossistemas com uma dependência mínima de insumos agroquímicos e energéticos externos. O objetivo é "[...] trabalhar com e alimentar os sistemas agrícolas complexos onde as interações ecológicas e sinergismos entre os componentes biológicos criem, eles próprios, a fertilidade do solo, a produtividade e a proteção das culturas" (ALTIERI, 2004, p. 23).

Por sua vez, Gliessman (2002) define esse enfoque agroecológico a partir dos princípios e conceitos da ecologia, em um desenho de agroecossistemas sustentáveis. De acordo com Eduardo Sevilla-Guzmán (2002), a agroecologia constitui o campo do conhecimento que promove o manejo ecológico dos recursos naturais, por meio de formas de ação social coletiva que apresentam alternativas à atual crise da modernidade. Essas alternativas seriam implantadas mediante propostas de desenvolvimento participativo, desde os âmbitos da produção e da circulação alternativa de seus produtos, no intuito de estabelecer formas de produção e de consumo que contribuam para enfrentar a crise ecológica e social e, desse modo, restaurar o curso alterado da coevolução social e ecológica.

O desenvolvimento local endógeno é o componente fundamental dessa estratégia, pois parte da valorização dos recursos e processos locais, mediante a participação ativa dos habitantes na gestão e controle do desenvolvimento ou pós-desenvolvimento como forma de recriar a heterogeneidade no espaço comunal de produção e de criar soluções tecnológicas específicas para cada agroecosistema (CASADO; SEVILLA-GUZMÁN; MOLINA, 2000), haja vista que "[...] as consequências de repensar o desenvolvimento local e os modelos locais são enormes” (ESCOBAR, 2005, p. 67). Essa transição agroecológica poderá ser executada num processo de operacionalização e transformação, com respaldo no conhecimento da população local. Para Sevilla Guzmán (2002, p. 19), a agroecologia é de "[...] natureza pluri-epistemológica e de prevalência de técnicas participativas, nas quais a metodologia utilizada tem uma natureza ou perspectiva de investigação dialética com a participação ativa da comunidade".

Em face do exposto, o presente estudo tem como objetivo abordar os aspectos agroecológicos previstos para a criação de uma Reserva de Desenvolvimento Sustentável (RDS) na localidade de Areais da Ribanceira, localizada em Imbituba, Santa Catarina.

\section{METODOLOGIA}

Para aprofundar o tema agroecologia, abordado na disciplina de Etnobiologia do Programa de Pós-Graduação em Ciências Ambientais da UNESC (PPGCA/UNESC), em nível de mestrado e doutorado, foi utilizado o método de ensino-aprendizagem estudo de caso (ABREU; MASETTO, 1985). Foi realizada uma saída de campo na comunidade dos Areais da Ribanceira, Imbituba - SC (Figura 1), em conjunto com os representantes da ACORDI, orientada pelos condutores ambientais 
“Taiá Terra”. O município de Imbituba localiza-se no litoral centro-sul de Santa Catarina, a 90 km ao sul da capital Florianópolis, e possui uma população aproximada de 40.170 habitantes (IBGE, 2010).

Figura 1 - Localização espacial dos Areais da Ribanceira de Imbituba/SC.
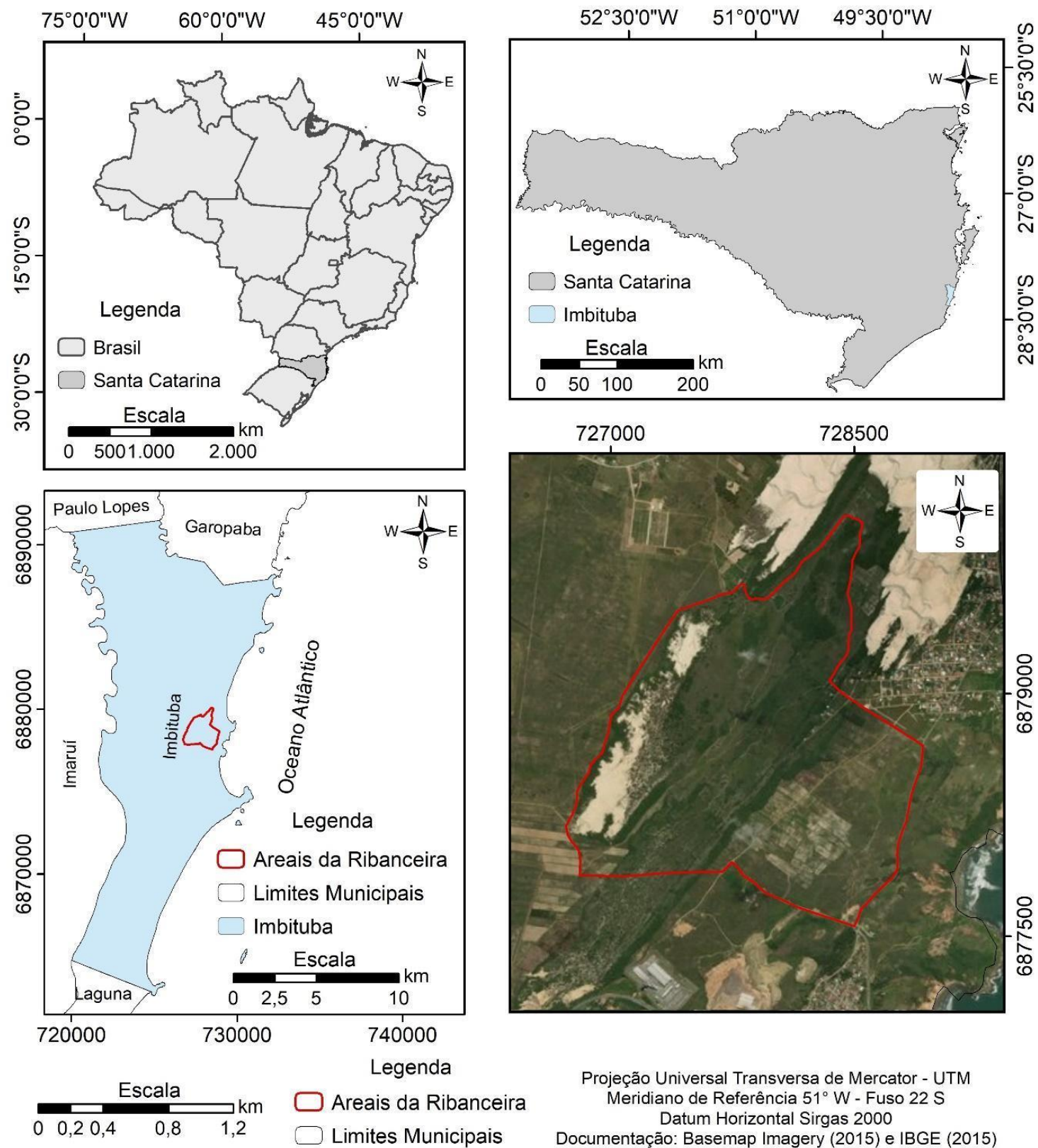

Projeção Universal Transversa de Mercator - UTM
Meridiano de Referência $51^{\circ}$ W - Fuso 22 S Datum Horizontal Sirgas 2000

Fonte: Elaborada pelos autores (2018).

Para reconhecer/conhecer a realidade, adotou-se uma abordagem de pesquisa qualitativa (AMOROZO; VIERTLER, 2010), utilizando como instrumento de coleta de dados a pesquisa observacional, com turnê guiada e documentário fotográfico (ALBUQUERQUE; LUCENA; ALENCAR, 2010). Como informação complementar aos resultados observados, foi consultada a Cartilha Areais da Ribanceira Dunas de Três Mares (CAMPOS PINTO et al., 2012) e bibliografia pertinente, sendo elas: Hanazaki et al. (2012), Zank e Hanazaki (2012) e Zank, Hanazaki e Mello (2015). 
Os resultados foram sistematizados e apresentados no formato de um seminário, objetivando socializar com os colegas e professores o tema e objeto deste estudo. Assim como o tema agroecologia, outros foram socializados na ocasião do encerramento da disciplina, como a pesca artesanal.

Após essa etapa, de explanação e socialização dos resultados, debatidos com base teórica, percepções individuais e do grupo, foi solicitada pelos docentes da disciplina a elaboração de um artigo científico.

\section{RESULTADOS E DISCUSSÃO}

A ocupação humana da região, objeto do estudo, é antiga, e foi a partir de 1715 que iniciou a formação da comunidade dos Areais da Ribanceira, constituída por imigrantes açorianos, bandeirantes e indígenas. Desde o processo de ocupação no século XVII, até o presente, as principais atividades são a agricultura e a pesca, ambas de caráter extrativista. Inicialmente, as principais atividades da região eram agricultura e pesca, na área rural, e atividades portuárias e da indústria cerâmica, na área urbana. Até a década de 1960, as famílias asseguravam sua subsistência mediante a combinação de atividades agrícolas, de pesca e de caça (SEIXAS; BERKES, 2005).

$\mathrm{Na}$ atualidade predominam agricultores familiares e pescadores artesanais, que procuram manter as lembranças do processo histórico de uso e ocupação da região, situada em um faixa litorânea no sul de Santa Catarina (MOMBELLI, 2011). Em 2010, aproximadamente 40 famílias de agricultores e pescadores tradicionais utilizavam como espaço os Areais da Ribanceira, estabelecendo, desse modo, o usufruto comum da terra. Coletivamente, realizam o preparo da terra, no entanto, no momento do plantio e pós-plantio, o trabalho torna-se individualizado por família. A agricultura é a principal fonte e forma de subsistência dos moradores, sendo que as terras cultivadas são de uso comum e a divisão das roças é feita por meio de acordos entre os agricultores (CAMPOS PINTO et al., 2012).

As práticas agrícolas de preparo das áreas de cultivo são, principalmente, desenvolvidas pelos homens, sendo que as mulheres atuam predominantemente no plantio e na colheita dos cultivos. Anualmente, por meio de acordos entre os agricultores, cada família utiliza cerca de dois hectares de terra da área de uso comum nos Areais da Ribanceira.

Formado por descendentes de açorianos, esse grupo social manteve-se no território, ao longo das gerações, graças ao sistema de uso comum tradicional, cujo manejo envolve principalmente cultivo de mandioca, extrativismo vegetal (butiá, ervas medicinais) e pesca artesanal. Areais da Ribanceira é considerado um mosaico ambiental, pela diversidade de recursos vegetais, principalmente de Manihot esculenta Crantz (mandioca e aipim), Butia catarinensis Noblick \& 
Revista Tecnologia e Ambiente, v. 25, 2019, Criciúma, Santa Catarina/SC ISSN Eletrônico 2358-9426 e ISSN Impresso 1413-8131

Lorenzi e Plantas Medicinais.

Ao efetuar o trabalho de investigação sobre a valorização do conhecimento, uso e manejo tradicional de recursos vegetais, como forma de colaborar para a efetividade de unidades de conservação de uso sustentável, com o envolvimento da comunidade dos Areais da Ribanceira nos processos de manejo e na tomada de decisão relacionados à conservação, Hanazaki et al. (2012) encontraram módulos de utilização de áreas de plantio anual que variam entre 0,5 a 5 ha e usadas por cerca de 6 meses a 2 anos, com intervalo de tempo de pousio de 1 a 5 anos. Nas entrevistas semiestruturadas, oficinas participativas e identificação de material botânico realizados, foram citadas trinta variedades de mandioca e quinze de aipim, usadas para a alimentação das famílias locais e para alimentar criações (suínos, bovinos).

As variedades de mandioca e aipim continuam circulando nas redes de trocas de ramas (mudas) entre parentes, vizinhos, amigos e conhecidos. Dessa forma, novas variedades chegam aos agricultores, bem como por meio do cruzamento das mudas plantadas nas roças. Essa metodologia de troca permite o aumento da agrobiodiversidade, fator fundamental para uma maior resistência do plantio, em relação a pragas e condições climáticas adversas. Nesse sentido, a valorização e transmissão dos conhecimentos tradicionais de cada comunidade acerca das plantas e suas variedades, assim como do seu uso e manejo, colaboram para a sustentabilidade agrícola e a conservação da agrobiodiversidade (PIERONI, 2014).

\section{MANDIOCA E O ENGENHO}

Há registro de cerca de trinta diferentes variedades de mandioca e quinze de aipim, sendo que a diferenciação entre elas depende do saber transgeracional dos agricultores, que observam partes da planta, como cor e a forma da rama; cor e forma da folha; cor da raiz; engalhamento, entre outros. Para ilustrar, veremos a seguir o depoimento de Alírio Bento da Silva e Antero F. Cardoso: "Mandioca torta rende bem e dá polvilho azedo" (A.B.S); "Aipim pêssego é macio, bom em qualquer terra e é bom para cozinhar" (A.F.C). Essa diversidade é reflexo de vários fatores, aspectos socioculturais como a peculiaridade do modo e estilo de vida, os hábitos alimentares consolidados ao longo do tempo e a manutenção de uma rede de troca de manivas-sementes (pedaço da rama de mandioca madura, entre 10 a 14 meses de idade, retirada do terço médio e inferior da planta matriz) entre os agricultores da comunidade e entre comunidades vizinhas (PEREIRA, 2013).

A principal diferença entre o aipim e a mandioca se dá com base na sua toxicidade alimentar, um requerendo apenas seu cozimento e outro um processo específico de desintoxicação, respectivamente, realizado no engenho. Algumas dessas especificidades do lugar possuem características como gênese histórica tão antiga que não há registros de quando e como chegaram às 
Revista Tecnologia e Ambiente, v. 25, 2019, Criciúma, Santa Catarina/SC ISSN Eletrônico 2358-9426 e ISSN Impresso 1413-8131

roças, outro fator que evidencia a importância da conservação do local. Os principais cultivos consorciados à mandioca dentro das roças incluem a Batata-doce (Ipomoea batatas (L.) Lam.); Cará (Dioscorea sp.); Melancia (Citrullus lanatus Schrad) e o Milho (Zea mays L.). Entretanto, as variedades de aipim e de mandioca (Manihot esculenta Crantz) são os recursos mais importantes no contexto agrícola local.

Para a manufatura da farinha, a comunidade dos Areais da Ribanceira conta com quatro engenhos em funcionamento, sendo dois de uso familiar, localizados no bairro da Ribanceira, e outro particular, localizado no bairro do Arroio, além de um comunitário, pertencente à Associação Comunitária Rural de Imbituba (ACORDI), localizado junto à sede da associação.

\section{BUTIÁ}

A coleta do butiá (Butia catarinensis Noblick \& Lorenzi) e da palha do butiazeiro representa uma das mais importantes práticas extrativistas que ocorrem na região dos Areais da Ribanceira. Segundo o conhecimento associado, o período de floração do butiazeiro é entre agosto e abril, e o de frutificação entre outubro e maio (auge do verão). O fruto do butiá é utilizado in natura como base para vários produtos alimentícios, dentre eles: doces, geleias, sucos, produção de cachaça, sorvetes, picolés, bolachas e pudins. Assim como o fruto, a palha do butiazeiro é utilizada para diversos fins, tanto utilitários para confecção de roupas, colchões, vassouras, telhados e chapéus, como também na forma de adornos e enfeites.

A produção dos cultivares e seus derivados, tanto da mandioca como do butiá, é inicialmente para uso familiar e comunitário, mas também ocorre a participação em feiras livres com exposição dos produtos artesanais como a farinha de mandioca e bijajica (quitute típico à base de massa de mandioca e amendoim), resultado da adaptação de uma receita ancestral indígena à influência da colonização europeia na região e produtos derivados de butiá.

Os líderes comunitários têm se esforçado, por meio de manifestações, na luta contra a depredação desse ecossistema, tão vulnerável às atividades antrópicas, como as queimadas ilegais que afetam significativamente a população de Butia catarinensis, espécie existente e endêmica do local.

\section{PLANTAS MEDICINAIS}

Os Areais da Ribanceira são caracterizados como um grande berço de plantas medicinais, que são utilizadas pelos moradores e representam a importância social da biodiversidade presente na área. Em um levantamento botânico realizado por Hanazaki et al. (2010), foram registradas 218 etnoespécies e, dessas, 197 foram identificadas pela taxonomia botânica como pertencentes a setenta 
famílias. As plantas medicinais são utilizadas principalmente para tratar problemas do sistema digestório, para dores e infecções de forma geral. Também foram citadas indicações terapêuticas para o sistema respiratório, como gripe e tosse; para o sistema circulatório, para problemas de pressão e coração, segundo relato dos moradores. Aproximadamente 36,5\% das espécies são obtidas nas dunas, matas (de restinga e de encosta), capoeiras, banhados e campos. Também na área de cultivo, há a produção sustentável de hortaliças em sistemas de permacultura.

A comunidade, por meio de uma oficina, elencou as dez plantas medicinais nativas mais importantes para a comunidade, identificadas por seus nomes populares e científicos, a saber: Cavalinha (Equisetum giganteum), Arnica (Calea uniflora), Cipó-mil-homens (Aristolochia triangularis), Espinheira-santa (Zollernia ilicifolia), Gervão-roxo (Stachytarpheta cayennensis), Guaco (Mikania laevigata), Mastruço (Coronopus didymus), Salsa-parrilha ou Cará (Dioscorea altissima), Marcela-do-campo (Achyrocline satureioides) e Quina, que não foi possível identificar porque não foram encontrados indivíduos, sendo essa planta citada também para benzeduras (HANAZAKI et al., 2010). As plantas foram organizadas em formato de quadro (Quadro 1), no qual constam: nomenclatura científica, nome popular (segundo os moradores locais) e os usos potenciais medicinais citados pela comunidade.

Quadro 1 - Plantas medicinais mais relevantes relatadas pelos moradores locais e sua utilidade para tratar enfermidades.

\begin{tabular}{|c|c|}
\hline \multirow{2}{*}{ Plantas Medicinais } & Informações segundo os moradores locais - Areais da Ribanceira \\
\hline & Usos Medicinais \\
\hline $\begin{array}{l}\text { Equisetum giganteum } \mathrm{L} \text {. } \\
\quad \text { (Cavalinha) }\end{array}$ & $\begin{array}{l}\text { Infecção, cistite, como antibiótico, para o tratamento de males do estômago, } \\
\text { intestino, fígado, bexiga, próstata e também para emagrecer. }\end{array}$ \\
\hline $\begin{array}{l}\text { Calea uniflora Less. } \\
\text { (Arnica) }\end{array}$ & $\begin{array}{c}\text { Dores em geral, cortes, machucados, ossos quebrados, para infecção, } \\
\text { azia e fezes com sangue. }\end{array}$ \\
\hline $\begin{array}{l}\text { Aristolochia triangularis } \\
\text { Cham. } \\
\text { (Cipó-mil-homens) }\end{array}$ & $\begin{array}{l}\text { Afinar o sangue, como digestiva, diabete, males da coluna, } \\
\text { rim e fígado, contra picada de insetos e veneno de aranha. } \\
\text { Citada por alguns para o tratamento de qualquer mal. }\end{array}$ \\
\hline $\begin{array}{l}\text { Zollernia ilicifolia (Brongn.) } \\
\text { Vogel } \\
\text { (Espinheira-santa) }\end{array}$ & Úlcera, pedra no rim, infecção de mulher, estômago e como calmante. \\
\hline $\begin{array}{l}\text { Stachytarpheta cayennensis } \\
\text { (Rich.) Vahl } \\
\text { (Gervão-roxo) }\end{array}$ & Fígado, hepatite, estômago, rim, bexiga e angina. \\
\hline $\begin{array}{l}\text { Mikania laevigata Sch. Bip. } \\
\text { ex Baker } \\
\text { (Guaco) }\end{array}$ & Tosse e gripe. \\
\hline Coronopus didymus (L.) & Infecção, esporão, pulmão, tosse, pontada, dor no corpo, ossos \\
\hline
\end{tabular}




\begin{tabular}{|c|c|}
\hline $\begin{array}{c}\text { Smith } \\
\text { (Mastruço) }\end{array}$ & $\begin{array}{c}\text { quebrados, queimadura, úlcera e feridas. } \\
\text { Uso alimentício nas saladas. }\end{array}$ \\
\hline $\begin{array}{c}\text { Dioscorea altissima Lam. } \\
\text { (Salsa-parrilha ou Cará) }\end{array}$ & $\begin{array}{c}\text { Circulação de sangue, "afinar o sangue", tratamento de "zipra", dores, corte, } \\
\text { digestiva, depurativa, colesterol, reumatismo, febre e } \\
\text { pressão alta. } \\
\text { Como alimento. }\end{array}$ \\
\hline $\begin{array}{c}\text { Achyrocline satureioides } \\
\text { (Lam.) DC. } \\
\text { (Marcela-do-campo) }\end{array}$ & Digestão e para emagrecer. \\
\hline $\begin{array}{c}\text { Quina } \\
\text { Sem identificação botânica }\end{array}$ & Diarreia, congestão, veneno, picada de cobra, ferida, sangue. \\
Usado para benzer.
\end{tabular}

Fonte: Adaptado de Hanazaki et al. (2010).

Além da utilização das plantas medicinais no contexto familiar, há a extração para comercialização e uso por pessoas externas da comunidade, em virtude do fácil acesso e ausência de demarcação territorial. A cavalinha, por exemplo, é extraída comercialmente pelos moradores locais e por pessoas externas; a espinheira-santa possui extração comercial, mas somente por pessoas externas, tendo relatos da chegada de caminhões para a extração da mesma; a marcela-do-campo possui extração por pessoas externas, inclusive de outros estados; e a Quina cuja extração desordenada das cascas por pessoas externas, resultando na morte da planta, o que justifica a escassez de exemplares para a identificação botânica na ocasião do levantamento realizado (HANAZAKI et al., 2010).

As principais ameaças às plantas medicinais, segundo os moradores, são a supressão por agentes externos à comunidade, dos ambientes de restinga e encosta de morros, já que a extração das plantas pelas comunidades locais é voltada principalmente para o uso familiar e não para o extrativismo intensivo.

O uso de plantas medicinais remonta ao início da humanidade, e esse saber oral repassado e mantido entre as gerações (DI STASI, 1996) se constitui um patrimônio imaterial da humanidade e deve ser preservado (IPHAN, 2018). Os patrimônios culturais imateriais são as crenças, as tradições valoradas pelas pessoas que fazem parte da cultura de um povo e que são transmitidas para os seus descendentes (IPHAN, 2018) e a ação antrópica coloca em risco a riqueza da biodiversidade e, consequentemente, os serviços ecossistêmicos (ANDRADE; ROMEIRO, 2009).

Apesar do avanço dos medicamentos sintéticos, as plantas medicinais e seus extratos são utilizados por aproximadamente $80 \%$ da população mundial. Esse número expressivo justifica-se pelo fato de que muitas comunidades não possuem acesso aos medicamentos sintéticos e, consequentemente, aos estabelecimentos de saúde, e outra parcela desse percentual prefere o tratamento fitoterápico, buscando uma terapia mais natural, sutil, eficaz e menos agressiva ao organismo quando comparado aos fármacos sintéticos (UICN, OMS, WWF, 1993; DI STASI, 1995; 
Revista Tecnologia e Ambiente, v. 25, 2019, Criciúma, Santa Catarina/SC ISSN Eletrônico 2358-9426 e ISSN Impresso 1413-8131

DE CASTRO BRANDÃO, 2009).

Assume-se hoje que a maior parte dos produtos farmacêuticos foi desenvolvida a partir dos produtos naturais. A despeito desse fato, estima-se que, das 300 mil espécies de plantas no mundo, apenas $15 \%$ delas tenham sido submetidas a algum estudo científico para avaliar suas potencialidades na preparação de novos produtos (NOGUEIRA; CERQUEIRA; SOARES, 2010). A contribuição dos produtos naturais no desenvolvimento de novos produtos farmacêuticos é inquestionável. Calcula-se que, somente nos últimos 25 anos, 77,8\% dos agentes anticancerígenos testados e aprovados foram derivados de produtos naturais que tiveram plantas utilizadas pelas comunidades (NOGUEIRA; CERQUEIRA; SOARES, 2010) e 25\% dos medicamentos prescritos em todo o mundo são de origem vegetal (RATES, 2001). Assim, é inegável o valor das plantas medicinais para o desenvolvimento de todas as etapas e da cadeia produtiva até chegar ao medicamento em si (NOGUEIRA; CERQUEIRA; SOARES, 2010).

Cabe destacar a espécie Varronia curassavica Jacq., presente na área de estudo, popularmente conhecida como erva-baleeira, utilizada no tratamento tópico de processos inflamatórios, que foi aprovada pela Agência Nacional de Vigilância Sanitária (ANVISA) para uso tópico das folhas em forma de infuso, como compressa ou em forma de pomada (ANVISA, 2011). Assim, a planta pode ser incorporada no Sistema Único de Saúde (SUS) de forma oficial, por atender aos preceitos legais que regulamentam a prescrição, fabricação e comercialização dos fitoterápicos em território nacional, objetivando garantir ao usuário segurança, qualidade e eficácia do tratamento (ANVISA, 2014).

\section{ACORDI - FEIRA DA MANDIOCA (MANIFESTAÇÃO CULTURAL DE RESISTÊNCIA E (RE) EXISTÊNCIA}

A Associação Comunitária Rural de Imbituba (ACORDI) constitui-se de agricultores e da comunidade local pertencente aos Areais da Ribanceira, em Imbituba/SC, que luta pelo reconhecimento e acesso à Justiça e construção de seus direitos. Os engenhos de farinha foram, até a década de 1970, a base da economia local, sendo movidos à tração animal até a chegada da energia elétrica, quando foram substituindo, aos poucos, os animais por motores.

Existe uma forte tradição, chamada "farinhada", que prevalece entre os moradores do local, para a produção da farinha, utilizando-se de práticas tradicionais milenares, realizada no engenho comunitário da ACORDI, reunindo amigos, familiares, jovens, idosos e crianças. Conforme Castellano (2015), o próprio turismo presente neste território, representa boas oportunidades para a oferta de produtos e serviços que valorizam os recursos materiais e imateriais específicos. Acontece ainda, anualmente (desde 2004, com duração de 3 ou 4 dias, geralmente em Junho - dia de São João e aniversário da ACORDI), a Feira da Mandioca, que reúne diversos visitantes, moradores e também 
Revista Tecnologia e Ambiente, v. 25, 2019, Criciúma, Santa Catarina/SC ISSN Eletrônico 2358-9426 e ISSN Impresso 1413-8131

pesquisadores em prol da contemplação, valorização e comercialização dos produtos artesanais/coloniais produzidos pela comunidade. A feira tem como propósito dar visibilidade à produção de farinha de mandioca produzidos pelos Agricultores e Pescadores Tradicionais dos Areais da Ribanceira. Esse evento também é palco de discussões referentes ao andamento dos trâmites legais, em função da conservação ambiental local, no qual participam a comunidade acadêmico-científica de universidades parceiras e pesquisadores interessados.

Ao longo das suas edições, a feira vem atraindo milhares de visitantes, contribuindo para um amplo debate com a sociedade sobre desenvolvimento sustentável, principalmente no que diz respeito ao meio ambiente, cultura, trabalho e à luta desenvolvida para manter o território dos Areais da Ribanceira. O evento resgata, ainda, outros patrimônios da cultura açoriana, como a rica gastronomia, artesanato, música e a dança.

A formação do capital social (BUARQUE, 2005) dos agricultores locais ao desenvolverem algumas práticas que podem ser consideradas como atividades de Manejo Comunitário de Biodiversidade, como a Feira da Mandioca e um engenho comunitário de farinha (ZANK, 2011), fortalece os elos de organização e cooperação onde o “[...] manejo comunitário na região dos Areais foi uma iniciativa da própria comunidade local, como uma forma de organização e luta por seus direitos de território" (ZANK, 2011, p. 84). A capacidade de ações articuladas em espaços institucionais de negociação e gestão, uma das premissas colocadas por Buarque (2005) como estratégia para a promoção do desenvolvimento local, está consolidada na atuação da ACORDI, que possui potencial de influência em relação às instituições externas, pois apresenta acesso aos tomadores de decisão em nível local (prefeitura) e federal (ICMBio, INCRA), além dos líderes e da organização serem reconhecidos tanto interna quanto externamente (ZANK, 2011).

No entanto, para assegurar a continuidade do "ecodesenvolvimento territorial" e prosseguir com um modelo contra hegemônico, para assegurar a gestão de recursos comuns, há que se rever alguns aspectos da forma de agregação de valor da cadeia produtiva da mandioca e seus derivados, em especial a farinha produzida, criando uma marca ou identidade própria que sirva para angariar recursos econômicos financeiros para serem distribuídos de forma igualitária entre os agricultores. Com este procedimento fica evidente a luta em defesa do modo de vida, de produção baseada em agrobiodiversidade e, principalmente, da cultura local.

Outro aspecto relevante diz respeito à manutenção e ampliação da capacidade de articulação institucional da ACORDI com universidades, institutos, fundações e organizações não governamentais para, em conjunto, estabelecer um plano de ação participativo, a fim de buscar, de forma equilibrada e consciente, outras possibilidades de renda já utilizadas, como as plantas 
medicinais e o butiá que pode ser, por meio de práticas de agroecologia, também produzidos em suas diferentes modalidades como a "agricultura orgânica", "permacultura" ou "agricultura sustentável".

No entanto, o território da ACORDI para atividades agroextrativistas de butiá, de plantas medicinais e principalmente de mandioca tiveram redução do espaço, desde a década de 1950. Como pontos de fragilidade ou vulnerabilidade local, essa redução de território é originária da política desenvolvimentista industrial local e nacional, além da constante ameaça exercida pela intensa especulação imobiliária existente na região. Atualmente, os agricultores têm a sua disposição apenas 24,3 hectares de terra para realizarem o plantio das roças itinerantes, devido à desapropriação de aproximadamente 250 ha da área do "Campo de Uso Comunal" ocorrida em outubro de 2010, reduzindo a menos de $10 \%$ o território disponível até então. Tal evento político-social deve ser considerado como um fator de risco à agrobiodiversidade local, devido à drástica redução das áreas de roças, além dos inestimáveis prejuízos sociais, imateriais e materiais às famílias agricultoras.

$\mathrm{Na}$ perspectiva sociopolítica e econômica atual de Imbituba, ocorre um etnocídio, caracterizado pela destruição da identidade cultural de um grupo étnico (STAVENHAGEN, 1985), pelo fato de a comunidade de agricultores/pescadores dos Areais da Ribanceira perder o território para a propagação não só das "ramas" de mandioca, mas também de sua identidade, que está atrelada à agricultura de subsistência e aos engenhos de farinha de mandioca.

O sistema de uso comunal de terras, combinado com a pesca artesanal e a extração do butiá, compõe um modo de vida que tem garantido a sobrevivência das famílias. Entretanto, a implementação de políticas públicas, centradas num processo de desenvolvimento hegemônico que prioriza os interesses do capital, tem ignorado o modo característico de vida e sua identidade cultural, favorecendo a instalação de polos industriais e empresas multinacionais ligadas à atividade portuária. As denominadas comunidades e povos tradicionais são, muitas vezes, percebidas meramente como entraves aos projetos de desenvolvimento e progresso.

Para continuarem a luta pelos direitos fundiários e a garantia de proteção do modo de produção sustentável, com práticas de agroecologia, proteção da agrobiodiversidade e da identidade cultural, entre as possibilidades estão as ações já desenvolvidas com o apoio de instituições universitárias, públicas e comunitárias, com organizações não governamentais para que consigam executar ações que monitorem os procedimentos jurídicos e administrativos em trâmite, perante o Ministério Público Federal (MPF), Incra/SC, ICMBio e Secretaria do Patrimônio da União.

Outras ações que poderiam contrapor o modelo hegemônico de desenvolvimento e construir de forma participativa a gestão ambiental do território, com princípios de desenvolvimento local sustentável, seriam: a) analisar as ações judiciais em curso e propor novas demandas jurídicas que se fizerem necessárias para assegurar os direitos da ACORDI; b) produzir estudos cartográficos e 
topográficos das áreas tradicionalmente ocupadas pelo sistema de uso comunal; c) promover oficinas sobre direito coletivo para a comunidade, voltadas à capacitação e instrumentalização política; d) realizar reuniões com instituições municipais, estaduais e federais, lideranças políticas, de movimentos sociais e sindicais da região; e) resgatar práticas e ações culturais locais como o Boi de Mamão e f) ampliar a visibilidade da luta, com divulgação de trilhas orientadas, envolvendo os moradores locais, em especial os jovens.

\section{CONSIDERAÇÕES FINAIS}

Da observação realizada in loco e os trabalhos consultados, evidenciam-se alguns aspectos básicos fundamentais para a reconstrução sustentável dos sistemas de produção, sendo eles a recomposição da fertilidade dos sistemas; a produção para o autoconsumo; a diversificação da produção; a transição agroecológica dos sistemas de produção; o fortalecimento e a melhoria dos sistemas de produção de mandioca em sistemas de cultivo em roças itinerantes; o resgate e a manutenção da produção de farinha nos engenhos; a ampliação e a diversificação de espécies vegetais, utilizadas de forma extrativista, em especial às plantas com potencial medicinal.

A comunidade, objeto deste estudo, adota princípios da agroecologia, pois em seu território há diversidade de espécies nativas e cultivadas, bem como as qualidades de todas as espécies cultivadas, adotando para isso um sistema agrícola itinerante e conhecimentos e práticas relacionados à agricultura e ao extrativismo. É evidente a luta da comunidade por promover a conservação da biodiversidade e cultura locais. Estudos aprofundados da área de butiazal que foi degradada, em face de queimadas criminosas, podem ser realizados no sentido de auxiliar na recuperação do local.

Assegurar o acesso à terra de forma comunitária, como vem sendo praticado pela comunidade dos Areais da Ribanceira, é fundamental para a reconstrução de uma nova proposta para a agricultura familiar/camponesa, com a recomposição sustentável dos sistemas de produção, baseados em princípios de agroecologia a fim de assegurar o modo de produção tradicionalmente passado, de geração em geração, e garantir a sobrevivência das próximas. Assim, engajar os jovens a permanecerem no local e preservarem esses conhecimentos que, durante gerações passadas, foram se concretizando é essencial.

O desafio da comunidade dos Areais da Ribanceira diz respeito à construção de uma proposta de agroecologia popular e transformadora que incorpore as dimensões tecnocientíficas e também dimensões sociológicas e políticas não capitalistas e transformadoras da sociedade. A agroecologia numa perspectiva transformadora pode ser assumida tanto numa condição mais tática de resistência e sobrevivência, mas, sobretudo na condição estratégica de enfrentamento do modelo agroindustrial e agroquímico hegemônico, de modo a estabelecer uma nova condição de relação produtiva positiva e de convivência/existência na natureza em defesa do território dos Areais da Ribanceira. A 
Revista Tecnologia e Ambiente, v. 25, 2019, Criciúma, Santa Catarina/SC ISSN Eletrônico 2358-9426 e ISSN Impresso 1413-8131

continuidade da promoção do desenvolvimento local em benefício da comunidade passa por assegurar a conquista do território atualmente utilizado e o resgate da parte "invadida" pelos agentes modificadores do espaço rural-urbano: indústrias atreladas ao terminal portuário e o avanço dos agentes formadores do espaço urbano de Imbituba/SC.

Em relação à atividade vivenciada pelos discentes e docentes, por meio da técnica estudo de caso na disciplina do PPGCA/UNESC, propiciou sedimentar conteúdos e observar, na prática, a realidade e a importância da agroecologia como ferramenta para preservação da biodiversidade e como argumento para resistência e (re) existência da comunidade, enquanto entidade/grupo cultural e social.

\section{REFERÊNCIAS}

ABREU, M. C.; MASETTO, M. T. O professor universitário em aula prática e princípios teóricos. 5. ed. São Paulo: Cortez, 1986.

ALBUQUERQUE; U. P.; LUCENA, R. F.; ALENCAR, N. L. Métodos e técnicas para coleta de dados etnobiológicos. In: ALBUQUERQUE, U. P.; LUCENA, R. F. P.; CUNHA, L. V. F. C. Métodos e técnicas na pesquisa etnobiológica e etnoecológica. Recife: PE: NUPEEA, 2010. p. 3964.

ALTIERI, M. Agroecologia: a dinâmica produtiva da agricultura sustentável. 4. ed. Porto Alegre: Editora da UFRGS, 2004.

AMOROZO, M. C. M.; VIERTLER, R. B. A abordagem qualitativa na coleta e análise de dados em etnobiologia e etnoecologia. In: ALBUQUERQUE, U. P.; LUCENA, R. F. P.; CUNHA, L. V. F. C. Métodos e técnicas na pesquisa etnobiológica e etnoecológica. Recife: PE: NUPEEA, 2010. p. $67-$ 82.

ANDRADE, D.C.; ROMEIRO, A.R. Serviços ecossistêmicos e sua importância para o sistema econômico e o bem-estar humano. Texto para Discussão, IE/UNICAMP, n. 155, fev. 2009, p. 1-45. ANVISA. Formulário de fitoterápicos, Farmacopeia Brasileira, Brasília - DF. 2011.

ANVISA. AGÊNCIA NACIONAL DE VIGILÂNCIA SANITÁRIA MS. RDC N. 26/2014. Dispõe Sobre o Registro de Medicamentos Fitoterápicos e o Registro e a Notificação de Produtos Tradicionais Fitoterápicos. Brasília - DF: DOU. 13 de maio de 2014. Disponível em: <http://bvsms.saude.gov.br/bvs/saudelegis/anvisa/2014/rdc0026_13_05_2014.pdf>. Acesso em: 25 jun. 2018.

BUARQUE, S. C. Construindo o desenvolvimento local sustentável: metodologia de planejamento. Rio de Janeiro: Garamond, 2002.

CAMPOS PINTO, M. F. et al. Areais da Ribanceira: dunas de três mares: biodiversidade e conhecimentos tradicionais: agricultura, plantas medicinais e extrativismo de butiá. Florianópolis: Laboratório de Ecologia Humana e Etnobotânica da UFSC, 2012. Disponível em: <https://pt.calameo.com/read/00081062427e20914bde1>. Acesso em: 25 jun. 2018.

CAPRA, F.; LUISI, P. L. A visão sistêmica da vida: uma concepção unificada e suas implicações filosóficas, políticas, sócias e econômicas. São Paulo: Cultrix, 2014.

CASADO, G. G.; SEVILLA-GUZMÁN, E.; MOLINA, M. G. Introducción a la agroecología como desarrollo rural sostenible. Madrid: Mundi-Prensa, 2000.

CASTEllano, F. O. Território e desenvolvimento rural: o caso dos engenhos de farinha de mandioca do litoral centro-sul de Santa Catarina. 2015. 120 f. Dissertação (Mestrado em Agroecossistemas). UFSC - Florianópolis, SC, 2015. 
DE AQUINO, A. M.; DE ASSIS, R. L. Agricultura orgânica em áreas urbanas e periurbanas com base na agroecologia. Ambiente \& Sociedade, Campinas, v. 5, n. 1, p. 137-150. 2007.

DE CASTRO BRANDÃO, D. A história da Fitoterapia no Brasil. In: ROLIM, S. M. (Ed.). Fitomedicamentos na prática ginecológica e obstétrica. São Paulo: ATHENEU, 2009. p. 1-11.

DI STASI, L. C. Plantas medicinais: arte e ciência: um guia de estudo interdisciplinar. São Paulo: Editora UNESP Fundação, 1996.

ESCOBAR, Arturo. O lugar da natureza e a natureza do lugar: globalização ou pós-desenvolvimento? In: LANDER Edgardo Lander (Org.). A colonialidade do saber: eurocentrismo e ciências sociais. Perspectivas latinoamericanas.Colección Sur Sur, CLACSO, Ciudad Autónoma de Buenos Aires, Argentina. 2005. p. 63-79.

GLIESSMAN, S. R. Agroecologia: processos ecológicos em agricultura sustentável. Porto Alegre: Ed. UFRGS, 2001.

HANAZAKI, N. et al. Etnobotânica nos Areais da Ribanceira de Imbituba: Compreendendo a Biodiversidade Vegetal Manejada para Subsidiar a Criação de uma Reserva de Desenvolvimento Sustentável. Bio Brasil: Biodiversidade Brasileira, Brasília, v. 2 n. 2, p. 50-64, 2012. Semestral. Seção: Uso e Manejo de Recursos Vegetais em Unidades de Conservação. Disponível em: <http://www.icmbio.gov.br/revistaeletronica/index.php/BioBR/article/download/273/185>. Acesso em: 17 jul. 2018.

IBGE, 2010. Panorama da população. Disponível em: <https://cidades.ibge.gov.br/brasil/sc/imbituba/panorama>. Acesso em: 29 jun. 2018.

IPHAN. Instituto de Patrimônio Histórico e Artístico Nacional. Patrimônio imaterial. Disponível em: <http://portal.iphan.gov.br/pagina/detalhes/234>. Acesso em: 25 ago. 2018.

UICN, OMS, WWF, 1993. Directrices sobre conservación de plantas medicinales Organización Mundial de la Salud (OMS). Unión Internacional para la Conservación de la Naturaleza (UICN) and World Wildlife Fund (WWF), Gland, Switzerland.

MOMBELLI, R. Comunidade tradicional dos Areais da Ribanceira, Imbituba (SC): desenvolvimento, territorialidade e construção de direitos. Revista Estudos de Sociologia: Dossiê: Conflitos Ambientais, Construção de Direitos e Território, Araraquara, v. 18, n. 35, p. 325-345, 2013.

MOMBELLI, R. Territorialidade e direito tradicional da Comunidade dos Areais da Ribanceira, Imbituba (SC). In: Encontro anual Associação Nacional de Pós-Graduação e Pesquisa em Ciências Sociais (ANPOCS), 35, 2011, Caxambu. Anais... Caxambu: ANPOCS, 2011. p. 1- 20.

MOMBELLI, R. et al (Orgs.). Nova cartografia social dos povos e comunidades tradicionais do Brasil: comunidade tradicional dos agricultores e pescadores dos Areais da Ribanceira. Manaus: UEA Edições, 2011. Projeto Nova Cartografia Social da Amazônia. (Povos e Comunidades Tradicionais do Brasil; 20). Disponível em: <http://novacartografiasocial.com.br/download/20comunidade-tradicional-dos-agricultores-e-pescadores-artesanais-dos-areais-da-ribanceira-

imbituba-sc/>. Acesso em: 23 jun. 2018.

NOGUEIRA R. C.; CERQUEIRA H. F.; SOARES M. B. P. Patenting bioactive molecules from biodiversity: the Brazilian experience. Expert Opinion Ther Patents, United Kingdom, v. 20, n. 2, p. 1-13, 2010.

PEREIRA, M. L. Valorização da agrobiodiversidade como estratégia de desenvolvimento territorial sustentável: estudo exploratório na zona costeira centro-sul de Santa Catarina. 2013. 194 f. Dissertação (Mestrado em Agroecossistemas) - Universidade Federal de Santa Catarina, Florianópolis, 2013.

PIERONI, G. C. Engenhos da cultura: teias agroecológicas. Florianópolis: Ponto de Cultura Engenhos de Farinha/Cepagro, 2014. .

RATES, S. M. K. Plants as source of drugs. Toxicon, v.39, n.5, p. 603-613, 2001.

SEIXAS, C. S.; BERKES, F. Mudanças socioecológicas na pesca da Lagoa de Ibiraquera, Brasil. In: VIEIRA, P. F.; BERKES, F.; SEIXAS, C. S. Gestão integrada e participativa de recursos naturais: conceitos, métodos e experiências. Florianópolis: APED \& SECCO, 2005, p. 113-146.

SEVILLA GUZMÁN, E. A perspectiva sociológica em Agroecologia: uma sistematização de seus 
métodos e técnicas. Agroecologia e Desenvolvimento Rural Sustentável, Porto Alegre, v. 3, n. 1, p. 18-28, 2002.

STAVENHAGEN, R. Etnodesenvolvimento: uma dimensão ignorada no pensamento desenvolvimentista. Anuário Antropológico/84. Rio de Janeiro: Tempo Brasileiro, 1985. p. 11-44. ZANK, S. et al. Empoderamento de Comunidades Rurais e o Estabelecimento de uma Reserva de Desenvolvimento Sustentável: Estudo de Caso nos Areais da Ribanceira, Imbituba - SC. Biodiversidade Brasileira, Brasília, v. 2, n. 2, p.33-49, 2012. Semestral. Instituto Chico Mendes de Conservação da Biodiversidade. Disponível em: <http://www.icmbio.gov.br/revistaeletronica/index.php/BioBR/article/view/272/220>. Acesso em: 13 jul. 2018.

ZANK, S.; HANAZAKI, N.; MELLO, A. S. Participatory Approaches and Conservation of Medicinal Plants: Identifying priority species in the community of Areais da Ribanceira (Brazil). Ethnobotany Research and Applications, v. 14, p. 357-366, 8 dez. 2015. Botanical Research Institute of Texas. Disponível em: 〈http://dx.doi.org/10.17348/era.14.0.357-366>. Acesso em: 23 jun. 2018.

ZANK, S.; HANAZAKI, N. Exploring the Links between Ethnobotany, Local Therapeutic Practices, and Protected Areas in Santa Catarina Coastline, Brazil. Evidence-based Complementary and Alternative Medicine, HINDAWI: Cairo - Egito, v. 2012, p.1-15, 2012. 